\title{
Komunikasi Pariwisata Kampung Kapitan di Palembang
}

\author{
Melinia Anggakesuma Tarana, Sinta Paramita \\ melinia.915170053@,stu.untar.ac.id,sintap@,fikom.untar.ac.id
}

Fakultas Ilmu Komunikasi Universitas Tarumanagara

\begin{abstract}
One of the historical tourist destinations in Palembang City is Kampung Kapitan. This place was the forerunner to the entry of the Chinese community in Palembang. Kapitan is a position given by the Dutch government to Tjoa Ham Ling to organize the administration of the Chinese community. For tourism in Palembang to develop, proper communication is needed to attract tourists. Therefore, this study aims to determine the efforts of managers in developing Kampung Kapitan tourism in Palembang, the form of tourism communication used by the tourism managers of Kampung Kapitan in Palembang, and the obstacles faced in developing tourism communication in Kampung Kapitan in Palembang. The approach used in this research is a qualitative approach with a case study method. There are also theories used in this research are communication strategy theory, marketing communication, and tourism communication. To complete this research required data collection. There are two data collection techniques in this study, that is primary data and secondary data. The results of the data were obtained through direct observation of Kampung Kapitan and interviews with four informants. This research concludes that the tourist destinations of Kampung Kapitan have several forms of tourism communication, including tourism marketing communication, brand destination, tourism communication management, tourism transportation communication, tourism visual communication, tourism group communication, and communication online tourism.
\end{abstract}

Keywords: communication strategy, kampung kapitan, marketing communication, tourism communication

\begin{abstract}
Abstrak
Kampung Kapitan merupakan salah satu destinasi wisata sejarah yang berada di Kota Palembang. Tempat ini merupakan cikal bakal masuknya masyarakat Tionghoa ke Palembang. Kapitan merupakan sebuah jabatan yang diberikan oleh pemerintah Belanda kepada Tjoa Ham Ling untuk mengatur administrasi bagi masyarakat Tionghoa. Agar pariwisata di Palembang dapat berkembang maka dibutuhkanlah komunikasi yang tepat agar dapat menarik wisatawan. Maka dari itu, penelitian ini bertujuan untuk mengetahui upaya pengelola dalam mengembangkan pariwisata Kampung Kapitan di Palembang, bentuk komunikasi pariwisata yang digunakan oleh pengelola pariwisata Kampung Kapitan di Palembang, dan kendala yang dihadapi dalam mengembangkan komunikasi pariwisata Kampung Kapitan di Palembang. Pendekatan yang digunakan dalam penelitian ini adalah pendekatan kualitatif dengan metode studi kasus. Ada pula teori yang digunakan dalam penelitian ini adalah teori strategi komunikasi, komunikasi pemasaran, dan komunikasi pariwisata. Untuk melengkapi penelitian ini dibutuhkan pengumpulan data. Terdapat dua teknik pengumpulan data dalam penelitian ini, yaitu data primer dan data sekunder. Hasil data diperoleh melalui observasi langsung ke Kampung Kapitan dan wawancara dengan empat narasumber. Kesimpulan dari penelitian ini adalah tempat wisata Kampung Kapitan memiliki beberapa bentuk komunikasi pariwisata, diantaranya komunikasi pemasaran pariwisata, brand destinasi, manajemen komunikasi pariwisata, komunikasi transportasi pariwisata, komunikasi visual pariwisata, komunikasi kelompok pariwisata, dan komunikasi online pariwisata.
\end{abstract}


Melinia Anggakesuma Tarana, Sinta Paramita: Komunikasi Pariwisata Kampung Kapitan di Palembang

Kata Kunci: kampung kapitan, komunikasi pariwisata, komunikasi pemasaran, strategi komunikasi

\section{Pendahuluan}

Pariwisata merupakan salah satu bentuk rekreasi bagi kebanyakan orang untuk menghabiskan hari liburnya bersama keluarga dan teman. Ada pula orang yang melakukan pariwisata sendiri untuk merasakan kebebasan dari hiruk pikuk seharihari. Data dari Kementerian Pariwisata dan Ekonomi Kreatif (Kemenparekraf) menunjukkan bahwa pada tahun 2018 kunjungan wisatawan mancanegara ke Indonesia pada bulan Desember berjumlah 1.405.554 kunjungan. Jumlah tersebut mengalami kenaikan sebesar 22,54\% dibandingkan pada tahun 2017 yaitu berjumlah 1.147.031 kunjungan. Hal ini didukung Pemerintah Indonesia dengan melakukan kegiatan promosi pariwisata dengan meluncurkan website resmi di bawah naungan Kementerian Pariwisata dan Ekonomi Kreatif. Indonesia Travel: The Official Website of Indonesia Tourism adalah website resmi dari pariwisata Indonesia yang berisikan tentang segala informasi pariwisata di Indonesia. Tidak hanya itu, website tersebut juga dapat memberikan rekomendasi tempat yang menarik kepada wisatawan yang ingin berpariwisata ke daerah tersebut.

Menurut Hardyanto dalam Mellisen (2005), pariwisata (tourism) adalah suatu soft power tersendiri. Maksudnya adalah pariwisata merupakan industri keempat terbesar di dunia dan tumbuh hampir dua digit persen per tahunnya. Maka dari itu, dalam rangka meningkatkan potensi pariwisata Indonesia. Pada tahun 2018 Pemerintah Indonesia mengambil strategi yang menetapkan sepuluh destinasi wisata baru. Destinasi wisata baru tersebut adalah "Sepuluh Bali Baru" (New Ten Bali). Destinasi tersebut antara lain Danau Toba di Provinsi Sumatera Utara, Tanjung Kelayang di Provinsi Bangka Belitung, Tanjung Lesung di Provinsi Banten, Kepulauan Seribu di Provinsi DKI Jakarta, Candi Borobudur di Provinsi Jawa Tengah, Kawasan Bromo-Tengger-Semeru di Provinsi Jawa Timur, Mandalika di Provinsi Nusa Tenggara Barat, Labuan Bajo di Provinsi Nusa Tenggara Timur, Wakatobi di Provinsi Sulawesi Tenggara, dan Morotai di Provinsi Maluku Utara (Humas Setkab, 2017).

Namun, dari Sepuluh Bali Baru tersebut wilayah Sumatera Selatan khususnya di Palembang tidak terdapat di dalamnya. Padahal pada tahun 2018, Kota Palembang pernah menjadi tuan rumah Asian Games 2018 selain Jakarta. Hal ini dapat membuat Palembang menjadi salah satu destinasi wisata bagi para wisatawan dalam dan luar negeri. Salah satu destinasi wisata di Kota Palembang adalah Kampung Kapitan. Kampung Kapitan terletak di tepi Ulu Sungai Musi, yaitu di sisi barat Jembatan Ampera atau di kawasan 7 Ulu Kecamatan Seberang Ulu 1 Palembang. pada masa pemerintah Belanda masyarakat China Palembang di kawasan 7 Ulu memiliki pemimpin yang bernama Tjoa Kie Tjuan yang bergelar Mayor. Ia memegang jabatan tersebut pada tahun 1830-1855. Kemudian digantikan putranya yang bernama Tjoa Ham Ling yang bergelar Kapten (Adiyanto, 2016). Dengan gelar yang dimilikinya maka kampung di kawasan 7 Ulu tersebut dinamai dengan Kampung Kapitan. Tjoa Ham Ling merupakan keturunan marga Tjoa yang kesepuluh.

Salah satu upaya untuk mengambangkan destinasi wisata adalah dengan menentukan strategi komunikasi. Strategi komunikasi diartikan sebagai gabungan perencanaan komunikasi (communication planning) dengan manajemen komunikasi (communication management) untuk mencapai tujuan yang telah ditetapkan. 
(Effendy, 2009) Salah satu strategi dalam komunikasi adalah komunikasi pemasaran yang menjadi upaya untuk membuat seluruh kegiatan pemasaran dan promosi perusahaan dapat menghasilkan citra atau image yang sama dan konsisten bagi konsumen (Morrisan, 2010). Dalam industri pariwisata, usaha yang dilakukan adalah dengan senantiasa menanggapi kebutuhan konsumen dan perkembangan produk yang mempengaruhi lingkungan pemasaran pariwisata (Utama, 2017). Menurut Burhan Bungin dalam, komunikasi pariwisata mempunyai beberapa bidang kajian utama yang dapat dikembangkan menjadi berbagai bidang kajian yang menarik (Dwijulianto dan Dewi, 2019)

Penulis melakukan penelitian ini agar dapat mengetahui, bentuk komunikasi pariwisata Kampung Kapitan di Palembang, serta untuk mengetahui upaya pengelola dalam mengembangkan pariwisata Kampung Kapitan di Palembang. Selain itu juga dengan penelitian ini juga dapat diketahui kendala yang dihadapi dalam mengembangkan komunikasi pariwisata Kampung Kapitan di Palembang.

\section{Metode Penelitian}

Penelitian ini menggunakan pendekatan kualitatif agar dapat mengungkapkan Komunikasi Pariwisata Kampung Kapitan di Palembang dengan mengumpulkan data dari proses dan makna berdasarkan perspektif subyek. Penelitian kualitatif adalah jenis penelitian yang hasilnya tidak diperoleh melalui prosedur statistik atau bentuk hitungan. Penelitian kualitatif bersifat deskriptif dan lebih menggunakan analisis dengan pendekatan induktif (Sugiarto, 2015). Dalam penelitian ini, peneliti menggunakan metode penelitian studi kasus untuk dapat mendalami bentuk komunikasi pariwisata di Kampung kapitan, serta untuk dapat mencari tahu upaya pengelola dalam mengembangkan pariwisata Kampung Kapitan. Creswell dalam buku Metode Penelitian Kualitatif menyatakan bahwa studi kasus adalah bagian dari metode kualitatif yang dilakukan untuk mendalami sebuah kasus secara lebih terperinci dengan mengumpulkan dari berbagai sumber informasi (Raco, 2010)

Dalam penelitian ini yang menjadi subjek penelitian adalah berupa tempat, yaitu Kampung Kapitan di Palembang. Kampung Kapitan merupakan sebuah kawasan cagar budaya yang beralamat di Jl. KH. Azhari, 7 Ulu, Kecamatan Seberang Ulu I, Kota Palembang, Sumatera Selatan. Sedangkan, objek penelitian dalam penelitian ini adalah komunikasi pariwisata yang digunakan di Kampung Kapitan. Teknik pengumpulan data dalam penelitian ini dilakukan dengan menggunakan data primer dan data sekunder. Dalam data primer, peneliti melakukan wawancara kepada informan kunci, informan dan narasumber. Sedangkan untuk observasi, peneliti melakukannya di Kampung Kapitan Palembang. Data sekunder yang digunakan dalam penelitian ini adalah dengan dokumentasi untuk mengumpulkan bukti-bukti dari objek yang diteliti (Sugiarto, 2015)

Crano dan Brewer dalam buku Analisis Data Kualitatif: Sebuah Tinjauan Teori dan Praktik, menyatakan bahwa terdapat langkah-langkah dalam menganalisis data pada studi kasus, yaitu: 1.) Menyusun fakta spesifik tentang kasus dalam suatu urutan logis. Dalam hal ini, peneliti melakukan transkrip data dari wawancara yang dilakukan peneliti bersama narasumber. 2.) Menggolongkan data ke dalam suatu kelompok yang memiliki makna tertentu. Makna tersebut dalam penelitian ini adalah komunikasi pariwisata. Jadi, peneliti akan menggolongkan data tersebut ke dalam komunikasi pariwisata. 3.) Menginterpretasikan sebuah kejadian spesifik dalam data yang mungkin berkaitan dengan penelitian. 4.) Menentukan pola dalam data. Pada 
Melinia Anggakesuma Tarana, Sinta Paramita: Komunikasi Pariwisata Kampung Kapitan di Palembang

tahap ini, peneliti akan menentukan apakah data tersebut sesuai dengan komunikasi pariwisata. 5.) Menyimpulkan. Penarikan kesimpulan ini sudah ada sejak awal dari pengumpulan data karena peneliti telah mencatat dan memberi makna dari yang dilihat dan diwawancarai.

\section{Hasil Temuan dan Diskusi}

Dalam buku Misteri Manuskrip Pusaka Kampung Kapitan di Palembang, dinyatakan bahwa "Kapitan" berasal dari bahasa Portugis yang berarti jabatan seseorang yang mengatur komunitasnya. Gelar Kapitan tidak berkaitan dengan jabatan pada militer, sehingga kapitan hanya berkuasa pada komunitasnya yaitu warga Tionghoa yang berada di wilayah tersebut. Gelar ini pun berlanjut dan menjadi turun-menurun hingga pemerintahan Hindia-belanda. Tugas yang dilakukan oleh Kapitan antara lain: mengurus perdagangan, memungut pajak, izin usaha, izin tinggal, mengurus surat lahir, dan surat kawin bagi warga Tionghoa. Kampung Kapitan terdiri atas tiga rumah peninggalan Kapitan pada abad ke-19. Rumah tersebut bergaya perpaduan antara rumah Limas Palembang dan rumah Eropa yang berpilar.

\section{Upaya Pengelola dalam Mengembangkan Pariwisata Kampung Kapitan di Palembang}

Sejak tahun 2010 Kampung Kapitan ditetapkan menjadi Cagar Budaya. Sehingga, Kampung Kapitan secara resmi dilindungi oleh Undang-Undang no. 11 Tahun 2010 Tentang Cagar Budaya, Nomor Urut 006, Nomor Registrasi Nasional PO2015010700005. Pengelola Kampung Kapitan, yaitu Mulyadi pada saat diwawancarai mengatakan bahwa senang apabila Kampung Kapitan menjadi tempat wisata sejarah yang dikenal banyak orang dari luar maupun dalam negeri. Menurut beliau, sebelum diresmikan oleh pemerintah Kampung Kapitan sudah ramai dikunjungi oleh wisatawan dari dalam maupun luar negeri. Selain ditetapkan menjadi Cagar Budaya, Kampung Kapitan juga mendapat perhatian dari Menteri Budaya Taiwan. Menurut Mulyadi, pagoda yang berada di taman depan rumah Kapitan merupakan salah satu bentuk bantuan dari Menteri Budaya di Taiwan dari bangsa Xiang Chu Tiongkok. Pagoda ini merupakan bentuk penghargaan terhadap leluhur suku Tionghoa yang berada di Palembang.

Tak hanya menjadi tempat wisata sejarah, Kampung Kapitan dalam tiga tahun terakhir ini juga dijadikan sebagai tuan rumah dalam perayaan Cap Go Meh. Selain perayaan Cap Go Meh, terdapat acara lain yang diadakan di Kampung Kapitan yaitu Kirab Sriwijaya. Kirab Budaya Garuda Sriwijaya merupakan festival yang dilakukan setiap tahunan yang dilakukan untuk mengembangkan keanekaragaman budaya tradisional yang telah membesarkan nama Kerajaan Sriwijaya. Kegiatan yang terdapat di Kampung Kapitan tidak hanya sebatas kegiatan budaya saja, melainkan ada juga kegiatan yang melibatkan anak-anak yang tinggal di sekitar Kampung Kapitan. Kegiatan tersebut adalah Rumah Belajar Kampung Kapitan. Rumah Belajar Kampung Kapitan ini merupakan salah satu dukungan dari Dinas Pariwisata Kota Palembang untuk mengembangkan wisata sejarah Kampung Kapitan. 


\section{Bentuk Komunikasi Pariwisata Kampung Kapitan di Palembang}

Menurut Burhan Bungin, komunikasi pariwisata mempunyai beberapa bidang kajian utama yang dapat dikembangkan menjadi berbagai bidang kajian yang menarik. Beberapa bidang kajian ini akan terus berkembang pada waktu yang akan mendatang sejalan dengan berkembangnya kompleksitas kajian di komunikasi pariwisata (Dwijulianto dan Dewi, 2019) Peneliti akan membahas Komunikasi Pariwisata di Kampung Kapitan berdasarkan bidang kajian menurut Burhan Bungin (Satvikadewi dan Hamim, 2018)

1. Komunikasi Pemasaran Pariwisata Kampung Kapitan di Palembang

Menurut analisa peneliti komunikasi pemasaran pariwisata yang ada di Kampung Kapitan, berupa acara Cap Go Meh yang diselenggarakan di Kampung Kapitan. Acara ini dapat membuat masyarakat yang biasanya mengikuti Cap Go Meh di Pulau Kemaro dapat berkunjung ke Kampung Kapitan yang merupakan tempat sejarah bagi warga Tionghoa di Palembang. Hasil dari acara Cap Go Meh yang diadakan di Kampung Kapitan adalah membuat Kampung Kapitan di liput oleh beberapa media. Setelah Kampung Kapitan di liput media maka masyarakat akan sadar dengan keberadaan Kampung Kapitan. Selain itu, Kampung Kapitan memiliki Instagram yang berfungsi untuk memberikan informasi kepada khalayak. Di Instagram itu juga berfungsi sebagai tempat promosi Kampung Kapitan dengan mengunggah foto-foto menarik dari Kampung Kapitan dan juga memberikan caption yang dapat mengundang daya tarik wisatawan.

2. Brand Destinasi Kampung Kapitan di Palembang

Kampung Kapitan termasuk dalam destinasi wisata sejarah yang memiliki bangunan sejak 400 tahun lalu. Bangunan ini tidak diubah sedikitpun demi mempertahankan keaslian dari bangunan tersebut. Sejarah dari Kampung Kapitan ini lah yang membuat daya tarik wisata tempat tersebut. Sehingga masyarakat akan mengenal Kampung Kapitan sebagai destinasi wisata yang mengandung sejarah di Palembang.

3. Manajemen Komunikasi Pariwisata Kampung Kapitan di Palembang

Pemasaran pariwisata yang ada di Kampung Kapitan berupa promosi melalui Instagram yang dikelola oleh tim TIC Kampung Kapitan. Lalu juga menurut Maulidia Wahyuni, bahwa biasanya terdapat brosur yang diletakan di Kampung Kapitan. Namun dikarenakan sedang Covid-19, maka brosur tersebut sedang tidak dicetak lagi.

4. Komunikasi Transportasi Pariwisata Kampung Kapitan di Palembang

Aksesibilitas untuk menuju ke Kampung Kapitan dapat ditempuh melalui dua cara. Pertama melalui darat dengan menggunakan kendaraan pribadi atau kendaraan umum. Kendaraan umum yang bisa digunakan di Palembang salah satunya adalah Light Rail Transit (LRT), lalu dilanjutkan dengan menggunakan ojek online atau angkutan umum. Kedua melalui sungai. Yang harus dilakukan untuk menuju ke Kampung Kapitan menggunakan jalur sungai adalah ke Benteng Kuto Besak (BKB) terlebih dahulu, lalu menaiki perahu ke dermaga Kampung Kapitan. Informasi seperti ini bisa didapatkan di internet dengan mudah. Selain itu juga, penjaga perahu yang berada di BKB sudah mengetahui apabila seorang wisatawan yang ingin 
menuju ke Kampung Kapitan. Letak Kampung Kapitan yang berada di tengah kota memudahkan wisatawan yang ingin berkunjung. Serta untuk wisatawan yang berasal dari luar kota Palembang juga dengan mudah menemukan hotel di dekat Kampung Kapitan.

5. Komunikasi Visual Pariwisata Kampung Kapitan di Palembang

Visual yang ditampilkan di Kampung Kapitan adalah bentuk bangunan yang sangat artistik. Bentuk bangunan dari Kampung Kapitan memiliki campuran dengan gaya Kolonial Belanda dan rumah panggung. Selain itu juga untuk membuat wisatawan selalu mengingat Kampung Kapitan, terdapat suvenir berupa baju yang bergambar rumah Kampung Kapitan.

6. Komunikasi Kelompok Pariwisata Kampung Kapitan di Palembang

Pemilik destinasi di Kampung Kapitan adalah Mulyadi yang merupakan keturunan ke-14 dari Kapitan. Mulyadi biasanya menjelaskan tentang sejarah Kampung Kapitan kepada pengunjung yang ingin mengetahui sejarah dari Kampung Kapitan secara jelas. Selain pemilik destinasi, di Kampung Kapitan juga memiliki pemandu wisata. Pemandu wisata yang berada di Kampung Kapitan merupakan dari Tourist Information Center (TIC). TIC sendiri dibentuk oleh Dinas Pariwisata Kota Palembang. Tugas TIC adalah memberikan informasi seputar Kampung Kapitan kepada pengunjung. Dengan adanya TIC, pengunjung mendapatkan informasi lebih banyak dan detail tentang Kampung Kapitan.

7. Komunikasi Online Pariwisata Kampung Kapitan di Palembang

Media online yang digunakan untuk menunjang komunikasi di Kampung Kapitan adalah media sosial Instagram. Dengan menggunakan Instagram, tim TIC mempublikasikan Kampung Kapitan. Apabila terdapat yang menarik, tim TIC akan mempublikasikan hal tersebut ke Instagram serta memberikan caption menarik dan juga ditambah dengan hashtag yang menyangkut dengan yang dipublikasikan.

\section{Kendala yang Dihadapi dalam Mengembangkan Komunikasi Pariwisata Kampung Kapitan di Palembang}

Menurut Mulyadi, kendala yang dialami dalam mengembangkan Kampung Kapitan adalah dalam segi keamanan, kebersihan dan ketertiban. Menurutnya, pemerintah hanya fokus pada bagian luar dari rumah Kapitan sedangkan untuk di dalam rumah Kapitan tidak terurus. Selain itu juga, agar pengunjung yang datang merasa aman, ketertiban harus dijaga. Dikarenakan Kampung Kapitan dikelilingi oleh masyarakat yang tinggal di dekatnya, terkadang tempat yang sudah bagus tibatiba ada orang yang merusak dan tidak bertanggung jawab. Mulyadi juga menambahkan bahwa beliau masih banyak menggunakan dana pribadi untuk merawat rumah Kapitan. Sedangkan menurut Marlin, banyak orang yang tidak mengetahui keberadaan Kampung Kapitan. Kebanyakan orang tahu bahwa Kampung Kapitan adalah sebuah restoran yang berada tak jauh dari lokasi tempat wisata Kampung Kapitan. 
Tabel 1. Bentuk Komunikasi Pariwisata Kampung Kapitan di Palembang

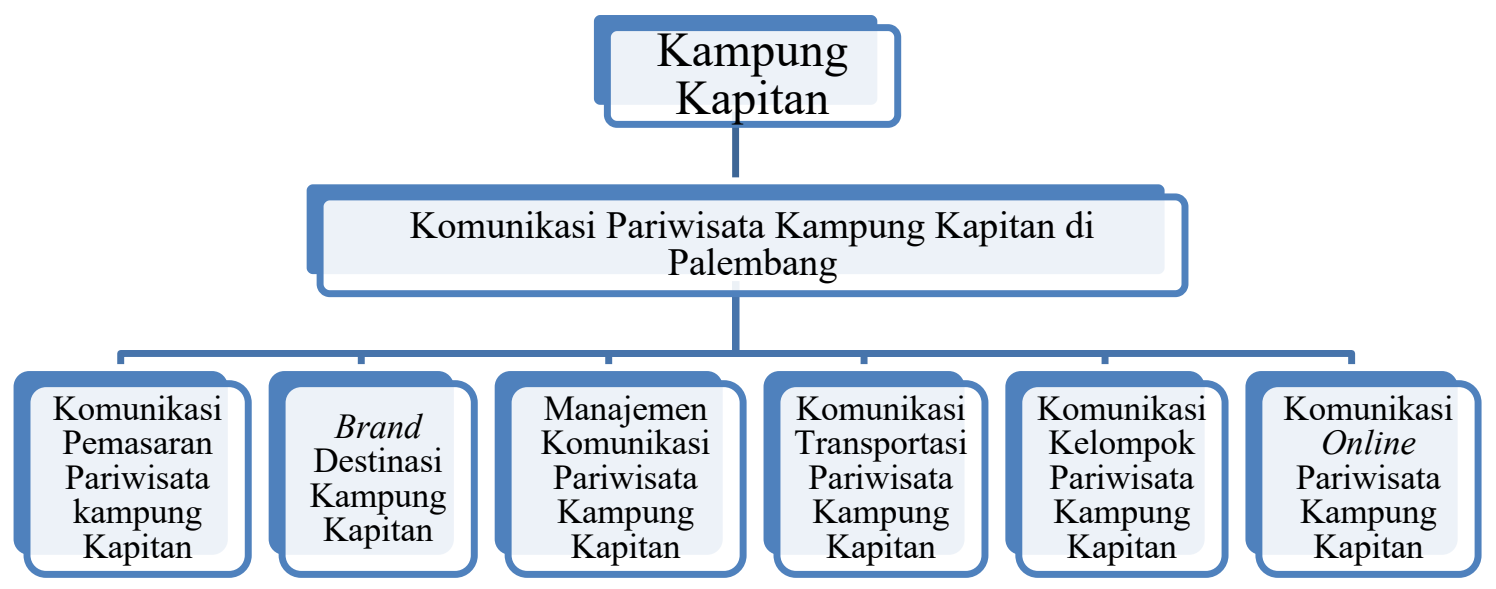

Sumber: Dokumentasi Peneliti (2020)

\section{Simpulan}

Berdasarkan hasil analisis dan temuan diatas dapat disimpulkan bahwa komunikasi pariwisata diperlukan dalam mengembangkan destinasi wisata agar dapat dikenal oleh publik. Terlebih lagi pada wisata sejarah yang perlu dijaga dan dilestarikan agar sejarah tersebut dapat tetap tersimpan dengan baik. Pengelola Kampung Kapitan berupaya agar tempat wisata sejarah tersebut tetap berdiri demi melestarikan sejarah yang pernah terjadi di tempat tersebut. Selain pengelola Kampung Kapitan, Dinas Pariwisata Kota Palembang juga turut berpartisipasi agar tempat tersebut tetap terjaga.

Bentuk komunikasi pariwisata yang ada di Kampung Kapitan, yaitu sebagai berikut: pertama, komunikasi pemasaran pariwisata yang melakukan pemasaran lewat Instagram. Kedua, brand destinasi melalui sejarah dari rumah Kapitan. Ketiga, manajemen komunikasi pariwisata yang dikelola tim TIC. Keempat, komunikasi transportasi pariwisata, informasi aksesibilitas ke Kampung Kapitan yang tersedia di aplikasi Google Maps. Kelima, komunikasi visual pariwisata yang dapat dilihat dengan bentuk suvenir baju yang dijual di tempat. Keenam adalah komunikasi kelompok pariwisata yaitu tim TIC yang menjadi pramuwisata di Kampung Kapitan. Ketujuh, komunikasi online pariwisata dengan memanfaatkan Instagram sebagai cara untuk memberikan informasi kepada wisatawan.

Peneliti harap dengan penelitian ini dapat menjadi masukan bagi para praktisi di bidang ilmu komunikasi terutama di bidang komunikasi pariwisata. Komunikasi pariwisata menjadi hal yang penting bagi sebuah tempat wisata agar dapat berkembang dengan baik. Komunikasi pariwisata dibutuhkan dalam mengembangkan sebuah destinasi wisata. Maka dari itu, penerapan komunikasi pariwisata menjadi salah satu tugas dari pengelola dan instansi yang berhubungan dengan pariwisata agar dapat meningkatkan minat wisatawan terhadap destinasi tersebut. Penting juga untuk memaksimalkan kenyamanan dan keamanan bagi wisatawan sehingga wisatawan dapat memberikan respon yang positif bagi destinasi tersebut. 
Melinia Anggakesuma Tarana, Sinta Paramita: Komunikasi Pariwisata Kampung Kapitan di Palembang

\section{Ucapan Terima Kasih}

Penulis mengucapkan terima kasih yang sebesar-besarnya kepada semua pihak yang telah membantu penulis selama melakukan penelitian ini. Terima kasih atas dukungan yang telah diberikan Universitas Tarumanagara dalam proses pelaksanaan penelitian.

\section{Daftar Pustaka}

Adiyanto, Johannes. (2016). Kajian Perubahan Ruang Terbuka pada Kawasan Bersejarah dengan Metode Space Syntax (Studi Kasus Kawasan Kampung Kapitan Palembang). Jurnal Perencanaan Wilayah dan Kota. 27(2). 105-106

Dwijulianto, Andri \& Dewi, P. A. R. (2019). Manajemen Komunikasi Pariwisata "The Spirit Of Majapahit” di Kabupaten Mojokerto. Commercium. 2(1). 2932

Effendy, O. U. (2009). Ilmu Komunikasi Teori dan Praktek. Bandung: PT Remaja Rosdakarya

Morrisan. (2010). Periklanan: Komunikasi Pemasaran Terpadu. Jakarta: Kencana

Raco, J. R. (2010). Metode penelitian Kualitatif Jenis, Karakteristik, dan Keunggulannya. Jakarta: PT Grasindo

Satvikadewi, A. A. I. P., \& Hamim. (2018). Strategi Komunikasi untuk Mempromosikan dan meningkatkan Potensi Lokal Wisata Pulau Bawean. Jurnal Representamen. 4(2). 79-91

Sugiarto, Eko. (2015). Menyusun Proposal Penelitian Kualitatif: Skripsi dan Tesis. Yogyakarta: Suaka Media

Utama, I. G. B. R. (2017). Pemasaran Pariwisata. Yogyakarta: CV Andi

Humas Setkab. (2017). Pesona Indonesia/Wonderful Indonesia: Inspirasi di balik Jenama Pariwisata Indonesia. Sekretariat Kabinet Republik Indonesia. $<$ https://setkab.go.id/pesona-indonesiawonderful-indonesia-inspirasi-di-balikjenama-pariwisata-indonesia/> (diakses pada 13 September 2020 pukul 19.48 WIB) 